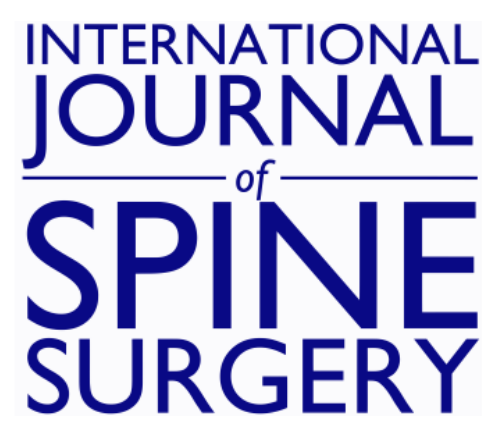

\title{
Patients Undergoing 3-Level-or-Greater Decompression-Only Surgery for Lumbar Spinal Stenosis Have Similar Outcomes to Those Undergoing Single-Level Surgery at 2 Years
}

Michael T. Nolte, Philip K. Louie, Bryce A. Basques, Arya G. Varthi, Justin C. Paul, Krishn Khanna, Tarush Khurana, Arshan Chaudhri, Dino Samartzis, Edward J. Goldberg and Howard S. An

Int J Spine Surg published online 22 September 2021

http://ijssurgery.com/content/early/2021/09/20/8124

This information is current as of April 26, 2023.

Email Alerts Receive free email-alerts when new articles cite this article. Sign up at: http://ijssurgery.com/alerts 


\title{
Patients Undergoing 3-Level-or-Greater Decompression- Only Surgery for Lumbar Spinal Stenosis Have Similar Outcomes to Those Undergoing Single-Level Surgery at 2 Years
}

\author{
MICHAEL T. NOLTE, MD, ${ }^{1}$ PHILIP K. LOUIE, MD ${ }^{2}$ BRYCE A. BASQUES, MD, ${ }^{1}$ ARYA G. VARTHI, MD, ${ }^{3}$ \\ JUSTIN C. PAUL, MD, PHD, ${ }^{4}$ KRISHN KHANNA, MD,${ }^{1}$ TARUSH KHURANA, BS, ${ }^{1}$ ARSHAN CHAUDHRI, \\ MS, ${ }^{1}$ DINO SAMARTZIS, DSC, ${ }^{1}$ EDWARD J. GOLDBERG, MD,${ }^{1}$ HOWARD S. AN, MD ${ }^{1}$ \\ ${ }^{I}$ Rush University Medical Center, Department of Orthopaedic Surgery, Chicago, Illinois, ${ }^{2}$ Hospital for Special Surgery, Department of Orthopaedic Surgery, \\ New York, New York, ${ }^{3}$ Yale School of Medicine, Orthopaedics, and Rehabilitation, New Haven, Connecticut, ${ }^{4}$ OrthoConnecticut, Danbury, Connecticut
}

\begin{abstract}
Background: Stability following multilevel decompressive laminectomy without fusion has been debated using in vitro biomechanical and radiographic models. However, there is a lack of information regarding clinical outcomes for these patients. The aim of the present study was to determine the association between clinical outcomes and number of levels decompressed via laminectomy for treatment of lumbar spinal stenosis.

Methods: We performed a retrospective cohort analysis of patients who underwent a primary lumbar laminectomy between 2009 and 2015 by senior orthopedic spine surgeons for lumbar spinal stenosis. Patients were divided into 2 groups based on the number of decompression levels: single level or 3 or more levels. Patient-reported outcomes were obtained in the form of Oswestry Disability Index (ODI) scores, visual analog scale (VAS) scores for the back and leg, 12-Item Short Form Mental and Physical Survey scores, and Veterans Rand 12-Item Health Mental and Physical Survey scores.

Results: Overall, 138 consecutive patients were assessed, of which 106 underwent a single-level and 32 underwent a 3-or-more-level laminectomy. Average follow-up was 24.2 months. There were no significant differences in the preoperative VAS back, VAS leg, or ODI scores between the single-level laminectomy and 3-or-more-level laminectomy groups. Both groups of patients experienced significant improvements in these clinical outcomes postoperatively with no clinically significant difference in the degree of improvement. Reoperation rates were low and similar between the 2 groups.

Conclusions: Patients undergoing decompression of 3 or more levels present with similar postoperative outcomes to those who undergo a single-level decompression for lumbar spinal stenosis. Under specific clinical and radiographic criteria, a multilevel decompression of 3 or more levels may be a safe and effective procedure with acceptable outcomes at 2 years after surgery.
\end{abstract}

Level of Evidence: 3.

Lumbar Spine

Keywords: lumbar spinal stenosis, multilevel laminectomy without fusion, decompression-only laminectomy, stabilitypreserving laminectomy

\section{INTRODUCTION}

STARTSymptomatic lumbar spinal stenosis (LSS) is a common pathology that often requires surgical intervention when patients have failed to improve with conservative treatment modalities. ${ }^{1-3}$ In patients with single-level stenosis, laminectomy has long been considered the standard of surgical care, with generally favorable outcomes. ${ }^{4}$ For multilevel stenosis, however, patients can be treated with either laminectomy alone or laminectomy plus lumbar fusion. ${ }^{2,5,6}$ While the addition of a fusion procedure has been supported for a number of patient populations (eg, degenerative spondylolisthesis, degenerative scoliosis, pars defects with disc disease, and symptomatic baseline instability), the merits of fusion in patients with multilevel stenosis alone is still debated. ${ }^{7-10}$ A potential benefit of fusion in patients undergoing multilevel laminectomy is that surgeons can resect more bone without 
concern for iatrogenic instability. However, an instrumented fusion procedure carries the risk of implant complications, longer surgical time, higher blood loss, and longer hospital stays and may predispose the patient to the development of symptomatic adjacent segmental degeneration/disease (ASD) and a need for revision surgery. ${ }^{11-14}$ Given these potential consequences, there has been growing interest in the outcomes following multilevel laminectomy alone for the treatment of LSS. Although the single-level laminectomy has long been considered an effective procedure when indicated for the right patient population, the relative effectiveness of the multilevel laminectomy without fusion has not been comprehensively explored.

A paucity of literature has attempted to analyze single versus multilevel laminectomy alone in patients with lumbar stenosis, and results have been mixed. Adilay and $\mathrm{Guclu}^{15}$ recently reported on 112 patients who underwent either single-level or multilevel lumbar laminectomy surgery without fusion for LSS and found that patients who underwent multilevel laminectomy reported worse postoperative Oswestry Disability Index (ODI) and visual analog scale (VAS) scores when compared to singlelevel laminectomy. On the other hand, Gunzburg et $\mathrm{al}^{16}$ analyzed 36 patients undergoing a limited laminectomy alone for lumbar stenosis, and found no association between the number of levels decompressed and patient reported outcome measures. Furthermore, the effectiveness of surgery is largely dependent on surgical technique. For example, an extensive decompression with partial or complete facetectomy can provide considerable relief from symptoms attributable to stenosis but may result in iatrogenic instability and a need for future instrumentation and fusion. Similarly, a limited decompression may result in preserved stability but inadequate relief of stenosis. Our group practices a stability-preserving technique with partial facetectomy to facilitate effective decompression that is highlighted below. Results regarding the safety and effectiveness of this surgical method for multilevel stenosis have yet to be published in the literature.

The aim of this study was to compare clinical outcomes of patients undergoing single-level laminectomy for lumbar stenosis with patients undergoing 3-or-more-level laminectomy alone for multilevel stenosis. We hypothesized that despite the potential for biomechanical instability based on in vitro studies, the clinical outcomes between the 2 groups of patients would be similar with no difference in the rate of revision surgery.

\section{MATERIALS AND METHODS}

\section{Patient Sample}

Following institutional review board approval, a retrospective cohort analysis of consecutive patients who underwent a primary lumbar decompression for a diagnosis of LSS between January 2008 and December 2015 was performed. Patients with previously diagnosed lumbar scoliosis, defined by a coronal Cobb angle of $>10^{\circ}$ who remained indicated for decompression-only surgery based on the judgment of the attending surgeon, were also included. Similarly, patients with spondylolisthesis that had less than $2 \mathrm{~mm}$ of translation on flexion and extension lumbar radiographs were included for analysis. The surgeries were performed by 1 of 2 senior orthopedic spine surgeons (H.S.A. and E.G.) at an academic medical center. Indications for surgery were radiculopathy and/or neurogenic claudication after failure of an appropriate course of conservative therapy. Patients received either a single level or multiple levels of decompression based on the distribution of their symptoms and the degree of stenosis on cross-sectional imaging. Patients were excluded from analysis if they were under 18 years of age at the time of surgery, had unstable or high-grade spondylolisthesis, had undergone a previous lumbar surgical procedure, or presented with an isolated herniated nucleus pulposus without underlying stenosis.

\section{Surgical Procedure}

Following induction of general anesthesia, all patients were positioned prone on a Jackson spine table, with neutral alignment of the lumbar spine. All surgeons wore loupes and headlamps to improve visualization during the decompression surgery. The surgical procedures were carried out using a standard posterior approach to the lumbar spine. Cephalad and caudal dissection was performed subperiosteally and did not extend beyond the midpoint of the spinous process of the supra- and subjacent vertebrae. Spinous processes of the necessary levels were completely removed. The laminae of the affected levels were initially thinned with a rongeur and high-powered burr. Laminectomy was subsequently performed with a Kerrison rongeur (Figure 1). Caution was taken not to extend 


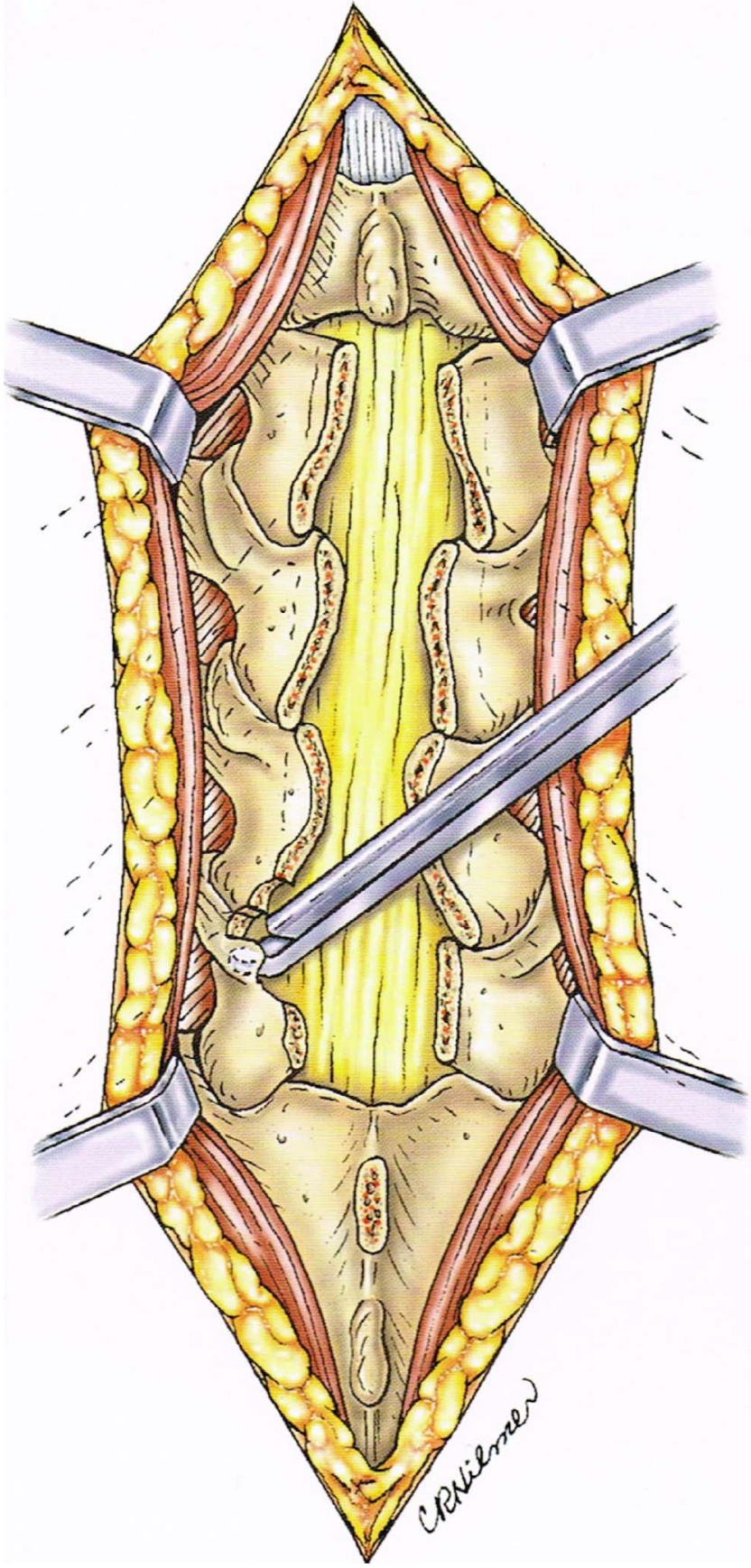

Figure 1. Multiple level lumbar decompression with completion of spinous processes and lamina removal from pathologic levels. A foraminotomy is being performed by following the nerve root into the foramen with the Kerrison rongeur. Final visualization should ensure that all affected nerve roots are free and mobile.

laminectomy wide at the pars interarticularis, attempting to preserve at least $6-7 \mathrm{~mm}$ of bone at the pars bilaterally. Depending on the severity of disease, a medial facetectomy was performed to ensure adequate decompression at pathologic regions. This facetectomy was performed with a Kerrison rongeur, with caution taken to avoid causing a defect in the pars. As typically there is no significant nerve root impingement at the pars, the laminectomy was purposefully narrower at the pars level and wider at the facet joints. If necessary, foraminotomies were then performed to adequately visualize exiting nerve roots at the symptomatic levels. The laminectomy was narrower in the more cephalad levels, as the pars is more medial than the caudal levels. If extruded disc fragments were observed, they were removed. Final visualization ensured that the affected nerve roots were free and mobile.

\section{Demographic and Outcome Measurements}

Demographic information was collected for all patients based on comprehensive chart review, including age (years), sex, body mass index (BMI; $\mathrm{kg} / \mathrm{m}^{2}$ ), diabetes, smoking status, and American Society of Anesthesiologists (ASA) physical status score. Patient-reported outcomes were obtained in the form of ODI scores, VAS scores for the back and leg, 12-Item Short Form Mental and Physical Survey (SF-12) scores, and the Veterans Rand 12Item Health Mental and Physical Survey (VR-12) scores. Reoperation rates were collected along with providing patients postoperative questionnaires that inquired about their satisfaction and expectations regarding their surgery. Questionnaires specifically asked if the patients' expectations were unmatched, matched, or exceeded and if patients were satisfied or not satisfied.

\section{Statistical Analysis}

Analysis was conducted using Stata version 13.1 (StataCorp LP, College Station, TX). The level of significance was set at $P<.05$. Baseline patient characteristics were compared using chi-square analysis and independent-sample $t$ tests for categorical and continuous data, respectively. Bivariate and multivariate regressions were subsequently used to compare clinical outcomes between procedure groups, with linear regressions used for continuous outcome scores and logistic regressions used for binary outcomes. Multivariate analyses controlled for any differences in baseline patient characteristics.

\section{RESULTS}

A total of 138 patients met criteria for inclusion, with 106 undergoing a single-level decompression and $32(23.2 \%)$ undergoing 3 or more levels of decompression. The mean age of all patients was 
Table 1. Demographics.

\begin{tabular}{|c|c|c|c|c|}
\hline & One Level & 3+ Levels & All Patients & $P$ Value $^{a}$ \\
\hline Overall & 106 & 32 & 138 & \\
\hline Age, mean $\pm \mathrm{SD}$ & $48.7 \pm 16.4$ & $67.9 \pm 8.7$ & $54.3 \pm 16.3$ & $<0.001$ \\
\hline Female sex, $\%$ & 36.79 & 31.25 & 34.43 & 0.765 \\
\hline $\mathrm{BMI}$, mean $\pm \mathrm{SD}$ & $28.7 \pm 6.8$ & $31.5 \pm 7.4$ & $29.5 \pm 6.5$ & 0.091 \\
\hline Smoking, \% & 6.60 & 12.50 & 8.02 & 0.560 \\
\hline Diabetes, \% & 11.32 & 37.50 & 15.57 & 0.001 \\
\hline $\mathrm{ASA} \geq 3, \%$ & 19.81 & 59.38 & 27.83 & $<0.001$ \\
\hline HNP, \% & 84.91 & 52.70 & 9.38 & $<0.001$ \\
\hline $\mathrm{CCI}$, mean $\pm \mathrm{SD}$ & $1.89 \pm 0.29$ & $3.15 \pm 0.46$ & $2.28 \pm 0.26$ & $<0.001$ \\
\hline
\end{tabular}

Abbreviations: ASA, American Society of Anesthesiologists score; BMI, body mass index; CCI, Charlson Comorbidity Index; HNP, herniated nucleus pulposus.

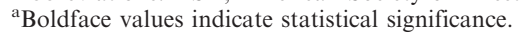

$54.3 \pm 16.3$ years (mean $\pm \mathrm{SD})$. Mean follow-up was 24.2 months (range 12-78 months). Patients who underwent decompression of 3 or more levels were significantly older $(67.9 \pm 8.7$ versus $48.7 \pm$ 16.4 years, $P<.001$ ) (Table 1 ). The multilevel decompression cohort also had a significantly greater percentage of patients with diabetes mellitus (37.50\% versus $11.32 \%$ for 1 level, $P=.001$ ) and a significantly greater percentage of patients with ASA score of 3 or more $(59.83 \%$ versus $19.81 \%$ for 1 level, $P<.001)$. There were no statistical differences between the 2 groups in regard to sex, BMI, or smoking status. There were 41 patients with scoliosis $(29.7 \%)$ and 26 patients $(18.8 \%)$ with low-grade spondylolisthesis in the study sample.
On multivariate analysis, there were no significant differences in any of the preoperative clinical outcome measures between patients who underwent 3 or more levels of decompression and those who underwent 1 level of decompression (Table 2). Similarly, there were no significant differences in any clinical outcome measures at the time of final assessment between the groups, nor were there any significant differences in the improvement of clinical outcome scores from preoperative to the final measure, as all patients showed improvement of scores following surgery.

There was no difference in the likelihood for reoperation following 3 or more levels of decompression $(6.45 \%$ versus $9.43 \%$ for single level, odds ratio $=4.46, P=.234)$. Reoperations were most

Table 2. Comparing clinical outcomes.

\begin{tabular}{|c|c|c|c|c|c|}
\hline & \multirow[b]{2}{*}{ One Level } & \multirow[b]{2}{*}{$3+$ Levels } & \multirow[b]{2}{*}{ All Patients } & \multicolumn{2}{|c|}{ Multivariate Analysis } \\
\hline & & & & Beta & $P$ Value \\
\hline \multicolumn{6}{|c|}{ Preoperative, mean $\pm \mathrm{SD}$} \\
\hline VAS back & $7.3 \pm 2.9$ & $6.9 \pm 2.6$ & $6.7 \pm 3.0$ & -0.54 & 0.590 \\
\hline VAS leg & $7.0 \pm 2.8$ & $5.1 \pm 3.4$ & $6.1 \pm 3.3$ & -2.02 & 0.066 \\
\hline ODI & $49.6 \pm 17.6$ & $40.7 \pm 8.0$ & $45.4 \pm 18.1$ & -8.03 & 0.117 \\
\hline SF-12 mental & $53.4 \pm 10.2$ & $54.2 \pm 4.6$ & $53.7 \pm 8.9$ & 2.56 & 0.664 \\
\hline SF-12 physical & $33.4 \pm 11.4$ & $30.4 \pm 14.7$ & $34.8 \pm 11.5$ & 5.97 & 0.411 \\
\hline VR-12 mental & $53.9 \pm 10.6$ & $53.7 \pm 0.9$ & $55.1 \pm 9.1$ & 0.83 & 0.906 \\
\hline VR-12 physical & $34.9 \pm 12.6$ & $29.4 \pm 18.4$ & $36.5 \pm 12.4$ & 4.05 & 0.678 \\
\hline \multicolumn{6}{|l|}{ Final, mean $\pm \mathrm{SD}$} \\
\hline VAS back & $2.7 \pm 2.6$ & $3.2 \pm 2.7$ & $3.2 \pm 2.8$ & 0.75 & 0.390 \\
\hline VAS leg & $2.2 \pm 2.5$ & $2.9 \pm 3.5$ & $2.7 \pm 3.0$ & 0.18 & 0.849 \\
\hline ODI & $22.3 \pm 19.1$ & $23.0 \pm 19.8$ & $24.6 \pm 19.7$ & -2.21 & 0.689 \\
\hline SF-12 mental & $52.5 \pm 11.1$ & $53.9 \pm 8.2$ & $53.1 \pm 9.6$ & 1.99 & 0.700 \\
\hline SF-12 physical & $38.7 \pm 13.8$ & $33.5 \pm 12.3$ & $38.6 \pm 13.0$ & -1.48 & 0.807 \\
\hline VR-12 mental & $55.1 \pm 11.7$ & $54.6 \pm 7.6$ & $55.5 \pm 10.4$ & 1.28 & 0.830 \\
\hline VR-12 physical & $41.8 \pm 14.5$ & $35.7 \pm 14.3$ & $41.1 \pm 13.6$ & -4.28 & 0.531 \\
\hline \multicolumn{6}{|c|}{ Change preoperative to final, mean \pm SD } \\
\hline VAS back & $5.1 \pm 3.4$ & $4.3 \pm 2.8$ & $4.4 \pm 3.6$ & -1.60 & 0.197 \\
\hline VAS leg & $5.2 \pm 3.8$ & $3.2 \pm 4.0$ & $3.9 \pm 4.5$ & -1.95 & 0.226 \\
\hline ODI & $31.4 \pm 21.5$ & $22.6 \pm 15.4$ & $25.9 \pm 21.8$ & -6.56 & 0.346 \\
\hline SF-12 mental & $2.1 \pm 9.8$ & 7.58 & $1.2 \pm 8.6$ & 8.08 & 0.491 \\
\hline SF-12 physical & $-8.3 \pm 13.6$ & -6.95 & $-7.9 \pm 13.0$ & -2.94 & 0.867 \\
\hline VR-12 mental & $0.5 \pm 11.1$ & 6.58 & $0.2 \pm 9.1$ & 5.52 & 0.660 \\
\hline VR-12 physical & $-10.5 \pm 14.4$ & -8.82 & $-8.8 \pm 13.6$ & -2.46 & 0.890 \\
\hline Reoperation, \% & 9.43 & 6.45 & 7.62 & 4.46 & 0.234 \\
\hline
\end{tabular}

Abbreviations: ODI, Oswestry Disability Index score; SF-12, 12-Item Short Form Mental and Physical Survey; VAS, visual analog scale score; VR-12, Veterans Rand 12Item Health Mental and Physical Survey. 
Table 3. Comparing binary clinical outcomes.

\begin{tabular}{|c|c|c|c|c|c|}
\hline & \multirow[b]{2}{*}{ One Level, \% } & \multirow[b]{2}{*}{$3+$ Levels, $\%$} & \multirow[b]{2}{*}{ All Patients, \% } & \multicolumn{2}{|c|}{ Three or More Levels } \\
\hline & & & & Odds Ratio & $P$ Value \\
\hline Satisfied with outcome & 87.50 & 100.00 & 92.21 & 0.11 & 0.126 \\
\hline Met or exceeded expectations & 97.06 & 100.00 & 98.11 & Omitted & Omitted \\
\hline
\end{tabular}

often due to disc herniation at the previously decompressed level or progression of degenerative disk disease. Specifically, 4 single-level patients $(3.8 \%)$ and 2 of the 3-or-more-level patients $(6.2 \%)$ underwent a revision to a posterior spinal fusion at the levels that were originally decompressed at a mean of 24 months (single level: 22.1 months; 3+ levels: 25.4 months) after the original surgery. Of these patients, $50 \%$ of both the singlelevel cohort $(\mathrm{N}=2)$ and 3-level cohort $(\mathrm{N}=1)$ had a low-grade spondylolisthesis at the operative level prior to their index surgery. The revision surgeries proceeded without complication, and all 6 patients reported satisfaction with their clinical outcome at 6-month follow-up from the revision procedure.

\section{DISCUSSION}

Lower-extremity radiculopathy and neurogenic claudication resulting from LSS have been shown to be responsive to surgical intervention, but the ideal procedural approach for multilevel stenosis remains debated. $^{3,17-19}$ The present study is the largest to date to analyze the relationship between clinical outcomes and number of levels decompressed via a stability-preserving laminectomy surgical technique without fusion. There were no significant differences in the final clinical outcome measures or the degree of improvement in these measures for patients with 3 or more levels of laminectomy compared to patients with single-level laminectomy across 7 widely utilized clinical assessment tools. There was no difference in the change in outcomes across the remaining 4 clinical assessment tools. Reoperation rates were low, and there were no significant differences in the likelihood for reoperation among the cohorts. Although the findings presented are of early to midterm clinical outcomes, a follow-up of 12-24 months has been suggested to be sufficient capturing the ultimate change in clinical outcomes following lumbar laminectomy and is consistent with prior literature. ${ }^{20-22}$ In fact, Ayling et $\mathrm{al}^{22}$ performed an analysis of lumbar laminectomy clinical outcome data from the Canadian Spine Outcomes and Research Network, finding that 12 months of follow-up is sufficient for capturing the plateaued effect of surgery on VAS back and leg scores (3 months), Disability Scale (12 months), and Short Form-12 Mental Component (3 months) and Short Form-12 Physical Component (3 months) scores.

Our findings are consistent with those of Gunzburg et al, ${ }^{16}$ who suggested there was no association between the number of levels decompressed and clinical outcomes. They prospectively analyzed 36 patients undergoing a conservative decompression surgery for LSS with a minimum of 1-year followup and found no differences in the preoperative, postoperative, or change in patient reported outcome measures between patients who underwent single-level decompression and those who underwent 2 or more levels of decompression. In the study, Gunzburg et al utilize a conservative surgical technique in which spinous process osteotomies were performed, with the processes being retracted to 1 side while the paraspinal musculature remains largely intact. This is in contrast to the traditional method of lumbar decompression, in which the paraspinal musculature is violated bilaterally and the spinous processes are removed from the field altogether. ${ }^{23}$ The authors hypothesized that the reduction in iatrogenic instability, following their soft tissue and spinous process preserving technique, may have explained the lack of differences in patient-reported outcomes between the 2 groups. Despite the differences in our surgical technique, we had similar findings. We hypothesize that an emphasis on preserving the integrity of the facet joints, while still performing adequate decompression, may explain the lack of iatrogenic instability and similar outcomes.

In contrast, Adilay and $\mathrm{Guclu}^{24}$ suggested that patients undergoing multilevel laminectomy alone for lumbar stenosis are likely to experience worse clinical outcomes compared to those undergoing single-level laminectomy. They compared 48 patients undergoing single-level laminectomy with 64 patients undergoing multiple levels of laminectomy with a minimum follow-up of 30 months and found that the multilevel cohort experienced worse post- 
operative ODI scores, VAS scores, and walking duration score. Furthermore, patients in the multilevel cohort were significantly more likely to experience subsequent spondylolisthesis and to undergo reoperation in the form of instrumented fusion. This latter finding may reflect that a more aggressive decompression was performed, contributing to iatrogenic instability and an increased likelihood of subsequent surgery.

Clearly, attention to surgical technique is critical for the optimal treatment of patients with lumbar stenosis. The degree of stability following decompression is thought to be dependent on the extent of the resection of bony and ligamentous structures, the loading forces applied to the involved segment(s), the condition of the intervertebral disc, and the global mobility of the spine. Previous biomechanical and radiological research has long suggested that range of motion of affected spinal segments increases as more posterior structures are violated. $^{25-27}$ In their original study of 12 human cadaveric units, Abumi et $\mathrm{al}^{26}$ found that singlelevel unilateral and bilateral medial facetectomy and unilateral and bilateral total facetectomies were associated with stepwise increases in the degree of flexion, extension, axial rotation, and lateral bending of the affected segment. In a similar study using a computer-generated spine model, Zander et $\mathrm{al}^{27}$ found that spinal column range of motion increases during forward flexion following single-level laminectomy with bilateral facetectomies and during standing and axial loading following 2-level laminectomy with facetectomies. Cardoso et $\mathrm{al}^{25}$ analyzed the effect of 1-, 2-, and 3-level laminectomies with bilateral facetectomy and instrumented fusion on the range of motion of adjacent segments in a human cadaveric model and suggested that the range of axial rotation, lateral bending, and flexionextension at the adjacent segment each increased significantly as the number of levels decompressed increased. However, no correlation could be made between this increase in range of motion and adverse clinical outcomes. Although valuable in hypothesis generation and in vitro understanding, the clinical significance of these studies has remained unclear, as cadaveric analysis cannot account for all stabilizing factors, and radiological findings have been shown to correlate poorly with symptomatology. ${ }^{28,29}$

If the surgeon is concerned about instability resulting from the decompression, an instrumented fusion can be performed in addition to the laminectomy. Bisschop et $\mathrm{al}^{30}$ performed a cadaveric analysis on single-level laminectomy with instrumented fusion. Their results showed a decrease in range of flexion/extension, lateral bending, and axial rotation each by $60 \%-74 \%$ at the affected segment and decreased range of lateral bending of the adjacent segment by $13 \%$. This was compared to single-level facet-sparing laminectomy without fusion, where there was an increase in the range of flexion/extension, lateral bending, and axial rotation each by $7 \%-12 \%$ at the affected segment. ${ }^{31}$ To assess clinical outcomes of fusion compared to nonfusion surgery for stenosis, Katz et $\mathrm{al}^{32}$ performed a retrospective cohort analysis of 272 patients with single-level degenerative stenosis following either laminectomy alone, laminectomy plus noninstrumented fusion, or laminectomy plus instrumented fusion and found no significant differences among the cohorts using several outcome assessments.

Despite the promising nature of the aforementioned studies, there are a number of disadvantages associated with the use of posterior instrumentation. Implant-related complications have been well studied and include infection, pseudarthrosis, nerve injury, increased blood loss during surgery with potential for transfusion, extended time of surgery, and instrumentation failure. ${ }^{11-14}$ Instrumented fusion also significantly increases the cost of surgery, and early reoperations are more common after laminectomy plus instrumented fusion when compared to laminectomy alone. ${ }^{33-35}$ There is also concern regarding the relationship between spinal fusion and development of adjacent segment disease. The pathogenesis of ASD is not well understood, but leading hypotheses attest that ASD is a result of the progression of the degeneration to segments other than those primarily affected or that instrumentation may adversely affect the stability of the adjacent levels with subsequent acceleration in degeneration. ${ }^{12,36}$ Regardless, literature describes that the instrumented fusion may be an independent risk factor for the development of ASD, with estimated reoperation rates for ASD as high $22.2 \%$ at 10 years postoperatively. ${ }^{37}$ Given these potential disadvantages, there is growing interest in the feasibility of decompressive laminectomy alone and the clinical outcomes following this procedure. In contrast to the majority of prior in vitro research and the limited and conflicting body of in vivo 
research, our generally positive clinical findings following decompression without fusion are likely explained by our intraoperative preservation of the entirety of the bilateral facet joints while providing enough decompression to result in symptomatic benefit.

The present study does have limitations. Prior to surgery, all patients underwent conservative management including physical therapy and use of antiinflammatory medications. However, there was heterogeneity in the type and length of therapy that we could not account for. Although these data feature the largest cohort of patients undergoing decompressive laminectomy alone, at 3 or more levels, the number of patients undergoing 3 or more levels of decompression was considerably smaller than the number undergoing single-level decompression. This inevitably decreased the power of our statistical analysis, and we were unable to adequately analyze whether group was equally likely to have their expectations met by the surgery. In addition, there were several baseline differences in demographics between the cohorts, with the 3-or-morelevel cohort having an older mean age, a greater percentage of patients with diabetes, and a greater percentage of patients with ASA score of 3 or more when compared to the single-level cohort. However, these differences may actually strengthen our conclusions, as older patients have typically been considered more likely to have instability and to be better candidates for fusion. ${ }^{10}$ Finally, these data reflect the work of only 2 surgeons, and clinical outcomes may reflect nuances in their surgical approach that were not necessarily accounted for by our multivariate analysis.

\section{CONCLUSIONS}

Although cadaveric and radiological studies have raised concern for instability, patients undergoing decompressive laminectomy without fusion at 3 or more levels experience similar postoperative and improved clinical outcome measures compared to patients undergoing a single-level decompression surgery. Future research should explore clinical outcomes following laminectomy alone compared to laminectomy plus fusion for patients with multilevel degenerative stenosis. Given the appropriate clinical scenario, a multilevel decompression without fusion appears to be a safe and effective procedure with acceptable outcomes at an average of 2 years after surgery.

\section{REFERENCES}

1. Bae HW, Rajaee SS, Kanim LE. Nationwide trends in the surgical management of lumbar spinal stenosis. Spine. 2013;38(11):916-926.

2. Thomé C, Zevgaridis D, Leheta $\mathrm{O}$, et al. Outcome after less-invasive decompression of lumbar spinal stenosis: a randomized comparison of unilateral laminotomy, bilateral laminotomy, and laminectomy. $J$ Neurosurg Spine. 2005;3(2):129-141.

3. Weinstein JN, Tosteson TD, Lurie JD, et al. Surgical versus nonsurgical therapy for lumbar spinal stenosis. $N$ Engl J Med. 2008;358(8):794-810.

4. Katz JN, Lipson SJ, Larson MG, McInnes JM, Fossel $\mathrm{AH}$, Liang $\mathrm{MH}$. The outcome of decompressive laminectomy for degenerative lumbar stenosis. $J$ Bone Jt Surg Am. 1991;73(6):809-816.

5. Ulrich NH, Burgstaller JM, Pichierri G, et al. Decompression surgery alone vs decompression plus fusion in symptomatic lumbar spinal stenosis: a Swiss prospective multicenter cohort study with three years of follow-up. Spine J. 2017;17(10):S164.

6. Lønne $G$, Fritzell $P$, Hägg $O$, et al. Lumbar spinal stenosis: comparison of surgical practice variation and clinical outcome in three national spine registries. Spine $J$. 2019;19(1):41-49.

7. Fischgrund JS, Mackay M, Herkowitz HN, Brower R, Montgomery DM, Kurz LT. 1997 Volvo Award winner in clinical studies. Degenerative lumbar spondylolisthesis with spinal stenosis: a prospective, randomized study comparing decompressive laminectomy and arthrodesis with and without spinal instrumentation. Spine (Phila Pa 1976). 1997;22(24):2807-2812.

8. Frazier DD, Lipson SJ, Fossel AH, Katz JN. Associations between spinal deformity and outcomes after decompression for spinal stenosis. Spine (Phila Pa 1976). 1997;22(17):2025-2029.

9. Cloward RB. Spondylolisthesis: treatment by laminectomy and posterior interbody fusion. Clin Orthop Relat Res. 1981;154:74-82.

10. Yone K, Sakou T, Kawauchi Y, Yamaguchi M, Yanase M. Indication of fusion for lumbar spinal stenosis in elderly patients and its significance. Spine (Phila Pa 1976). 1996;21(2):242-248.

11. Cassinelli EH, Eubanks J, Vogt M, Furey C, Yoo J, Bohlman HH. Risk factors for the development of perioperative complications in elderly patients undergoing lumbar decompression and arthrodesis for spinal stenosis: an analysis of 166 patients. Spine. 2007;32(2):230-235.

12. Ghiselli G, Wang JC, Bhatia NN, Hsu WK, Dawson EG. Adjacent segment degeneration in the lumbar spine. $J$ Bone Jt Surg. 2004;86(7):1497-1503.

13. Jutte PC, Castelein RM. Complications of pedicle screws in lumbar and lumbosacral fusions in 105 consecutive primary operations. Eur Spine J. 2002;11(6):594-598.

14. Pihlajamaki H, Myllynen P, Bostman O. Complications of transpedicular lumbosacral fixation for non-traumatic disorders. J Bone Jt Surg Br. 1997;79(2):183-189.

15. Adilay U, Guclu B. Comparison of single-level and multilevel decompressive laminectomy for multilevel lumbar spinal stenosis. World Neurosurg. 2018;111:e235-e240.

16. Gunzburg R, Keller T, Szpalski M, Vandeputte K, Spratt K. Clinical and psychofunctional measures of conserva- 
tive decompression surgery for lumbar spinal stenosis: a prospective cohort study. Eur Spine J. 2003;12(2):197-204.

17. Park DK, An HS, Lurie JD, et al. Does multilevel lumbar stenosis lead to poorer outcomes? A subanalysis of the SPORT lumbar stenosis study. Spine. 2010;35(4):439-446.

18. Burnett MG, Stein SC, Bartels RH. Cost-effectiveness of current treatment strategies for lumbar spinal stenosis: Nonsurgical care, laminectomy, and X-STOP. J Neurosurg Spine. 2010;13(1):39-46.

19. Lønne G, Fritzell P, Hägg O, et al. Lumbar spinal stenosis: comparison of surgical practice variation and clinical outcome in three national spine registries. Spine $J$. 2019;19(1):41-49.

20. Haddadi K, Ganjeh Qazvini HR. Outcome after surgery of lumbar spinal stenosis: a randomized comparison of bilateral laminotomy, trumpet laminectomy, and conventional laminectomy. Front Surg. 2016;3:19.

21. Nerland US, Jakola AS, Giannadakis C, et al. The risk of getting worse: Predictors of deterioration after decompressive surgery for lumbar spinal stenosis: A multicenter observational study. World neurosurgery. 2015;84(4):1095-1102.

22. Ayling OG, Ailon $\mathrm{T}$, McIntosh $\mathrm{G}$, et al. Clinical outcomes research in spine surgery: what are appropriate follow-up times? J Neurosurg Spine. 2018;30(3):397-404.

23. Hermansen E, Moen G, Fenstad AM, Birketvedt R, Indrekvam K. Spinous process osteotomy to facilitate the access to the spinal canal when decompressing the spinal canal in patients with lumbar spinal stenosis. Asian Spine $J$. 2014;8(2):138.

24. Adilay U, Guclu B. Comparison of single-level and multilevel decompressive laminectomy for multilevel lumbar spinal stenosis. World Neurosurg. 2017.

25. Cardoso MJ, Dmitriev AE, Helgeson M, Lehman RA, Kuklo TR, Rosner MK. Does superior-segment facet violation or laminectomy destabilize the adjacent level in lumbar transpedicular fixation? An in vitro human cadaveric assessment. Spine (Phila Pa 1976). 2008;33(26):2868-2873.

26. Abumi K, Panjabi MM, Kramer KM, Duranceau J, Oxland T, Crisco JJ. Biomechanical evaluation of lumbar spinal stability after graded facetectomies. Spine (Phila Pa 1976). 1990;15(11):1142-1147.

27. Zander T, Rohlmann A, Klockner C, Bergmann G. Influence of graded facetectomy and laminectomy on spinal biomechanics. Eur Spine J. 2003;12(4):427-434.

28. Fox MW, Onofrio BM, Onofrio BM, Hanssen AD. Clinical outcomes and radiological instability following decompressive lumbar laminectomy for degenerative spinal stenosis: a comparison of patients undergoing concomitant arthrodesis versus decompression alone. J Neurosurg. 1996;85(5):793-802.

29. Volkheimer D, Malakoutian M, Oxland TR, Wilke HJ. Limitations of current in vitro test protocols for investigation of instrumented adjacent segment biomechanics: critical analysis of the literature. Eur Spine J. 2015;24(9):1882-1892.

30. Bisschop A, van Engelen SJ, Kingma I, et al. Single level lumbar laminectomy alters segmental biomechanical behavior without affecting adjacent segments. Clin Biomech (Bristol, Avon). 2014;29(8):912-917.

31. Bisschop A, Holewijn RM, Kingma I, et al. The effects of single-level instrumented lumbar laminectomy on adjacent spinal biomechanics. Global Spine J. 2015;5(1):39-48.

32. Katz JN, Lipson SJ, Lew RA, et al. Lumbar laminectomy alone or with instrumented or noninstrumented arthrodesis in degenerative lumbar spinal stenosis: patient selection, costs, and surgical outcomes. Spine (Phila Pa 1976). 1997;22(10):1123-1131.

33. Deyo RA, Nachemson A, Mirza SK. Spinal-fusion surgery - the case for restraint. N Engl J Med. 2004;350(7):722726.

34. Kuntz KM, Snider RK, Weinstein JN, Pope MH, Katz JN. Cost-effectiveness of fusion with and without instrumentation for patients with degenerative spondylolisthesis and spinal stenosis. Spine (Phila Pa 1976). 2000;25(9):1132-1139.

35. Epstein NE. A review: reduced reoperation rate for multilevel lumbar laminectomies with noninstrumented versus instrumented fusions. Surg Neurol Int. 2016;7(suppl 13):337.

36. Helgeson MD, Bevevino AJ, Hilibrand AS. Update on the evidence for adjacent segment degeneration and disease. Spine J. 2013;13(3):342-351.

37. Sears WR, Sergides IG, Kazemi N, Smith M, White GJ, Osburg B. Incidence and prevalence of surgery at segments adjacent to a previous posterior lumbar arthrodesis. Spine $J$. 2011;11(1):11-20.

Disclosures and COI: The authors did not receive any funding or financial support for this project. None of the authors received payments, benefits, or services, either directly or indirectly, from a third party in support of any aspect of this work.

Corresponding Author: Michael T. Nolte, MD, Department of Orthopaedic Surgery, Rush University Medical Center, 1611 West Harrison Street, Suite 200, Chicago, IL 60612. Phone: (312) 563-6306; Fax: (312) 942-2040; Email: Mtnolte@ gmail.com.

Published 0 Month 2021

This manuscript is generously published free of charge by ISASS, the International Society for the Advancement of Spine Surgery. Copyright @ $\odot 2021$ ISASS. To see more or order reprints or permissions, see http://ijssurgery.com. 